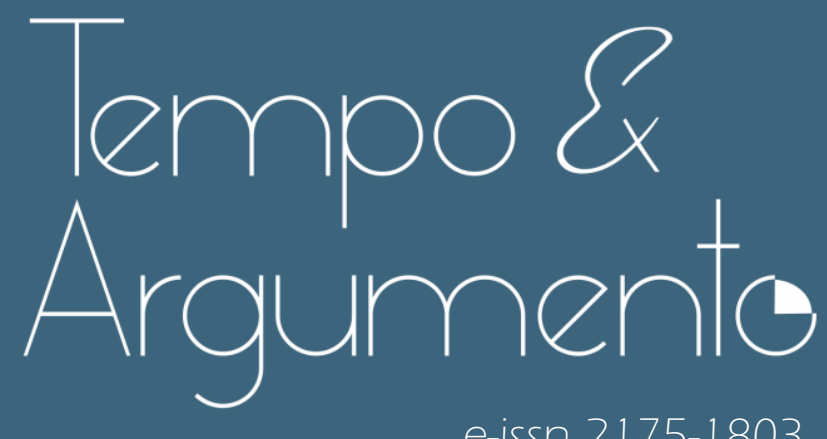

e-issn 2175-1803

\title{
Refugiados e a Guerra Civil Síria: análise e perspectivas sobre o acolhimento na Turquia
}

- Marcos Alan S. V. Ferreira

Doutor em Ciência Política pela Universidade Estadual de Campinas (UNICAMP).

Professor da Universidade Federal da Paraíba (UFPB) e professor visitante

no Mestrado em Desenvolvimento Social da Universidade Núr (Bolívia).

Bolsista Produtividade Nível 2 - Conselho Nacional de Desenvolvimento

Científico e Tecnológico (CNPq).

João Pessoa, PB - BRASIL

lattes.cnpq.br/4997359951496727

marcosalan@gmail.com

(i) orcid.org/0000-0002-3196-6508

Para citar este artigo:

FERREIRA, Marcos Alan. Refugiados e a Guerra Civil Síria: análise e perspectivas sobre o acolhimento na Turquia. Tempo e Argumento, Florianópolis, v. 13, n. 32, e0 108, jan./abr. 2021.

doi http://dx.doi.org/10.5965/2175180313322021e0108

Recebido: 27/10/2020

Aprovado: 09/02/2021 


\title{
Refugiados e a Guerra Civil Síria: análise e perspectivas sobre o acolhimento na Turquia
}

\begin{abstract}
Resumo
O presente artigo examina um aspecto central na Guerra Civil Síria, a saber, o acolhimento de refugiados de guerra na Turquia. Em especial, também se traçam cenários para esse acolhimento a partir da realidade atual do conflito armado. Metodologicamente, a pesquisa fundamenta-se na triangulação de dados que combinam bibliografia especializada, documentos sobre o tema provenientes de organizações humanitárias e ACNUR, à luz da literatura de avaliação de cenários internacionais. A Turquia foi um dos países que mais acolheu sírios desde o início do conflito armado na Síria em 2011. Neste contexto, a pesquisa aborda essa iniciativa e os desafios enfrentados pelo país devido à grande quantidade de refugiados em seu território, refletindo também sobre as perspectivas para esse acolhimento. Para isso, o artigo inicialmente apresenta a definição de refugiados e a contextualização do conflito sírio que provocou a saída de muitos civis. Em seguida, examina-se o acolhimento humanitário realizado pela Turquia e os desafios que surgiram ao longo desses anos em que o conflito perdura. Por fim, busca-se construir três possíveis cenários para a guerra civil síria e o acolhimento dos refugiados.
\end{abstract}

Palavras-chave: Refugiados. Síria - História - Guerra civil, 2011- . Humanitarismo. Turquia. Cenários Prospectivo.

\section{Refugees and Syrian Civil War: analysis and perspectives on reception in Turkey}

\begin{abstract}
This article examines a key issue of the Syrian Civil War: the war refugees in Turkey. In particular, the article also outlines scenarios for this refugees' reception based on the current status of the armed conflict. Methodologically, the research is grounded on the triangulation of data that combine specialized bibliography, documents from humanitarian organizations and UNHCR information on the subject, in the light of the literature evaluating international scenarios. Turkey has been one of the countries that has welcomed Syrians since the beginning of the armed conflict in Syria in 2011. In this context, the research addresses this initiative and the challenges faced by the country due to the large number of refugees in its territory, also reflecting on the prospects for this reception. Thus, the article initially presents the definition of refugees and the contextualization of the Syrian conflict that caused the departure of many civilians. It then examines Turkey's humanitarian reception and the challenges that have arisen over years in which the conflict persists. Finally, it seeks to build three possible scenarios for the Syrian civil war and the reception of Syrian refugees.
\end{abstract}

Keywords: Refugees. Civil War. Syria - history - Civil War, 2011- . Humanitarian. Turkey. Prospective Scenarios 


\section{Introdução1}

O conflito armado da Síria entra em 2021 em seu décimo ano e continua a provocar sofrimento marcante ao povo sírio. Iniciada em 2011 com revoltas pacíficas contra o presidente sírio Bashar al-Assad, a guerra civil alcançou proporções assustadoras, com o resultado até então de pelo menos 384.000 mortes (SOHR, 2020). O conflito teve início com revoltas de grupos opositores que desejavam a saída do presidente, emulando os movimentos em defesa de direitos políticos na Tunísia e Egito intitulados pela mídia como Primavera Árabe.

Assim como naqueles países - e posteriormente em outros da região - a sociedade civil questionava as autocracias do Oriente Médio, a limitação de liberdades civis e confrontavam frontalmente os que desejavam a permanência dos regimes. Os embates ganharam maiores proporções quando outros atores também entraram em conflito com o governo e outros grupos domésticos, o que foi o caso de grupos extremistas como o Estado Islâmico (ISIS) na Síria. Somase aqui interesses geopolíticos de atores regionais e internacionais no conflito (tais como Irã, Turquia, EUA e Rússia), que perpetuaram um conflito que tem proporcionado, além das mortes, mazelas como deslocamentos internos e uma crise de refugiados sem precedentes na região (ANDRADE, 2011; SOARES, 2018).

Em consequência do conflito, os sírios são hoje a maior população de refugiados do mundo com 5,5 milhões de pessoas forçadas a saírem de seu país desde 2011 (UNHCR, 2020). De acordo com o Alto Comissariado das Nações Unidas para os Refugiados (ACNUR/UNHCR), os refugiados sírios sob seu monitoramento estão espalhados em diversos países, em que se destacam Turquia, Líbano, Jordânia e Egito. A Turquia é o principal país que acolhe esse grupo e já conta com mais de 3 milhões de sírios em seu território (UNHCR, 2020). No que se refere ao posicionamento turco frente ao conflito sírio, o país inicialmente apoiou grupos que desejavam a retirada de Bashar al-Assad, porém também acolheu os refugiados com uma perspectiva inicial de que seria um evento temporário. Atualmente, o mais preocupante é que não há perspectiva de quando o conflito terá uma conclusão definitiva (WEBER, 2017).

\footnotetext{
Agradecemos aqui a dedicação e esforço de Evellin C. da Silva (Programa de Pós-Graduação em Gestão Pública e Cooperação Internacional - UFPB) pelo suporte com a cuidadosa coleta de dados e comentários sobre as análises apresentadas no decorrer deste artigo.
} 
Em um cenário de conflito permanente que intensifica deslocamentos espaciais, torna-se necessário entender os elementos que provocam esse fluxo, assim como os desafios para o país que os acolhe. Tal tema é central nos debates contemporâneos sobre conflitos armados e movimento de populações, como apresentado pela literatura especializada (FARIAS; FERREIRA, 2020; GARCÍA; MASSARAT, 2019; IÇDUYGU; NIMER, 2019; LUQUINI, 2017).

Neste contexto, o presente trabalho examina um aspecto central na Guerra Civil Síria, a saber, o acolhimento de refugiados de guerra na Turquia. Em especial, traçam-se também cenários para esse acolhimento a partir da realidade atual. Como a Turquia é um dos países que mais recebe refugiados sírios, além de ter interesses geopolíticos relacionados ao próprio conflito, a pesquisa foca em sua iniciativa de acolhimento desde o início da guerra até os dias atuais.

Ao construir cenários que considerem a contemporaneidade da temática, o artigo se pauta em uma metodologia qualitativa fundamentada em triangulação de dados. Este método mostra-se adequado para nosso objeto por permitir corroborar evidências com a combinação de múltiplas fontes, algo central para um fenômeno em desenvolvimento e com significante disputa de narrativas (SALKIND, 2010). Como fontes, utilizam-se a bibliografia especializada para definir conceitos e apresentar os contextos, mas também é apresentado o posicionamento de órgãos como a ACNUR e a própria Organização das Nações Unidas (ONU) como contraponto na análise, assim como de reconhecidos institutos de pesquisa que têm publicado policy papers sobre a temática. Assim, apresenta-se uma base consistente para refletir sobre os possíveis desdobramentos para o caso dos refugiados sírios.

Como um dos principais motivos para a saída dos sírios de seu país é o conflito armado, foram construídas na análise três perspectivas possíveis para o tema em questão. Tais panoramas possibilitam aos pesquisadores compreender os caminhos que o conflito pode tomar e desenvolver pesquisas futuras de um tema da história do tempo presente. Esses cenários consistem em perspectivas possíveis para o acolhimento de refugiados sírios e são uma análise necessária, pois por causa do crescimento acelerado das incertezas e mudanças que 
caracterizam o século XXI, podem existir diversas possibilidades para esse acolhimento. Neste sentido, pauta-se aqui, de acordo com Buarque (2003), quando este afirma que não é possível predizer o futuro, mas sim entender o contexto e observar os fenômenos sociais em andamento. A partir disso, apresentam-se as possíveis tendências que podem envolver esse cenário, assim como os atores ali presentes, o que por sua vez permite indicar os caminhos para futuras pesquisas de um tema contemporâneo (BUARQUE, 2003).

No primeiro cenário, considera-se que a guerra civil continua; no segundo, o conflito tem uma conclusão; e no terceiro, a guerra ainda perdura, mas existe o posicionamento e assistência mais efetivas da comunidade internacional com relação aos refugiados. A partir dos três cenários para o conflito armado na Síria, apresentam-se contextos recentes que podem influenciar em tendências futuras.

O trabalho a seguir se estrutura da seguinte forma: na próxima seção, é apresentada uma definição sobre refugiados e seus direitos, e contextualiza-se o problema do conflito sírio que tem provocado um grande número de refugiados; na segunda seção o foco é no acolhimento realizado pela Turquia e os desafios que emergiram ao longo desses anos com o aumento de refugiados em seu território; por fim, a terceira seção apresenta três perspectivas analíticas do cenário futuro e as possíveis consequências para o acolhimento de refugiados sírios na Turquia. Na última seção apresenta-se uma conclusão sobre os principais pontos destacados ao longo da pesquisa, assim como as possíveis soluções futuras para a quantidade de refugiados na Turquia.

\section{Migrações Internacionais Irregulares: o fenômeno e os refugiados}

As migrações internacionais são um fenômeno caracterizado pelo fluxo de pessoas entre diferentes países, regiões e continentes. Ele envolve em geral diversos grupos sociais que se movimentam por diferentes razões, proporcionando diferentes implicações socioeconômicas (PATARRA, 2006). Estima-se que no ano de 2019 existiam 272 milhões de migrantes internacionais, segundo a Organização Internacional para as Migrações (IOM, 2019). Ao longo dos anos, esses fluxos migratórios têm se acentuado, o que tem feito com que 
muitos países adotem políticas migratórias restritivas para ingresso em seu território (LOTERO-ECHEVERRI; RODRIGUEZ, 2019; MARCIAL, 2015). Ao invés de reduzirem os fluxos, essas políticas migratórias mais restritivas podem deixar esses migrantes em situação vulnerável e sem seus direitos fundamentais. Adicionalmente, também fazem com que a migração seja vista apenas como um "problema" a ser resolvido e uma ameaça à soberania nacional, ignorando o fato que de trata-se de um fenômeno social que requer claras políticas públicas de integração à comunidade (GARCÍA; MASSARAT, 2019; IMDH, 2019).

Há também os casos das migrações irregulares, como as "forçadas"; entre elas, o deslocamento interno e induzido por desastres e crises, asilo político e o refúgio. Acerca do asilo político, este é concedido para pessoas que não podem retornar ao seu estado de origem por causa de perseguição, mas sua concessão é estritamente política e não há procedimentos ou requisitos. Sobre refúgio, apesar dos termos "migrantes" e "refugiados" serem por muitas vezes utilizados como se fossem sinônimos, de acordo com Anne Inojosa (2019) há uma diferenciação que precisa ser feita entre os emigrantes e os refugiados (INOJOSA, 2019).

Os refugiados são aqueles que estão fora de seu país de origem por causa de perseguições, conflitos ou violências de alta periculosidade que impossibilitem seu retorno diante do risco à vida. Esse grupo necessita de uma proteção conhecida por "Proteção Internacional dos Refugiados" e que também envolve a ação da ACNUR para registro dos indivíduos e garantia de que tenham acolhimento humanitário e acesso às necessidades básicas, tais como saúde, água e educação (LOTERO-ECHEVERRI; RODRIGUEZ, 2019). No que se refere à proteção dos refugiados, esta última está respaldada no Direito Internacional Humanitário, destacando-se como dispositivos internacionais de garantia destes direitos a Convenção das Nações Unidas relativa ao Estatuto dos Refugiados de 1951 e o Protocolo de 1967 (SPINDOLA, 2018).

A Convenção de 1951 reconhece o refugiado regularmente com diversos direitos, entre eles o acesso ao emprego e ao sistema de saúde. O país que os acolhe deve ter a responsabilidade de proteger e de "não devolução" (nonrefoulement), o que pode mudar nos casos em que o refugiado represente algum 
perigo iminente ao país que o acolheu. Como o acolhimento humanitário de refugiados é um procedimento que demanda vários encargos e despesas, estas últimas recaem principalmente sobre o país ao qual o refugiado pediu refúgio, muito embora outros países e organizações possam também contribuir e fornecer ajuda humanitária (FURTADO, 2017). Por sua vez, o Protocolo de 1967 consolida e fornece a legislação sobre os direitos dos refugiados e as medidas básicas para seu tratamento. Fica em evidência que os refugiados têm direito ao asilo e segurança, além de serem incluídos os direitos fundamentais que são inerentes a qualquer indivíduo conforme as convenções internacionais de direitos humanos (BARICHELLO; ARAUJO, 2014).

A Guerra Civil Síria é um dos casos de instabilidade que desencadeou a movimentação humana de milhões de refugiados, o que demandou a aplicação dos instrumentos legais acima citados. O aumento desses refugiados fez também emergir o questionamento sobre quais Estados ratificaram a Convenção de 1951 e quais seriam as possibilidades para o acolhimento de tantos sírios (SHARMA, 2015). Neste debate, emergem como três principais opções a i) integração local no primeiro país que acolheu esses refugiados, ii) o reassentamento e iii) a repatriação voluntária (IÇDUYGU; NIMER, 2019). Dentre tais condições, o reassentamento remete aos casos de países que recebem por tempo limitado até que esses refugiados sejam transferidos para um outro país. Segundo a ACNUR (2019), esse tipo de ação consiste em um terceiro país receber e garantir a permanência desses indivíduos em seu território. O caso dos refugiados que migraram da Síria para a Turquia é emblemático aqui, pois no decorrer da guerra muitos deles têm permanecido em solo turco por um tempo até serem acolhidos em outro país. Sobre a repatriação, esta pode apenas ocorrer pelo desejo do próprio refugiado ou da ACNUR, muito embora o ideal seja que aconteça apenas se existir um contexto de paz e estabilidade no país de origem (HOFFMANN; SAMUK, 2016).

Em síntese, nos dois dispositivos internacionais mencionados anteriormente, há países signatários que aceitam e deveriam se comprometer em cooperar com a ACNUR para garantir que qualquer pessoa que necessite de refúgio possa ser ajudada. Logo, esses refugiados não podem ser vistos apenas 
como migrantes internacionais, pois isso pode afetar seu pedido de refúgio e impedir que cruzem fronteiras sem autorização. Apesar de ser uma migração irregular, torna-se necessário entender a motivação para a saída desses indivíduos de seu país de origem, já que estes não estão em busca apenas de um local com melhores empregos e oportunidades, mas saem muitas vezes por medo diante de uma situação extrema que coloca a vida em risco iminente (SPINDOLA, 2018). Esse é o caso dos refugiados sírios que deixaram o país devido ao conflito armado que perdura desde 2011, conflagração esta que provocou mais de meio milhão de mortos, deslocamentos, refúgios e uma séria crise humanitária.

\subsection{A Guerra Civil Síria: a crise humanitária e os refugiados sírios}

A Guerra Civil Síria tem sua gênese em 2011 em Daara, cidade ao sul do país, quando emergem manifestações em busca de mudanças políticas frente ao governo autocrata de Bashar al-Assad. As revoltas são reprimidas duramente pelo governo e se intensificam posteriormente (SOARES, 2018). No entanto, é considerado que o marco de início do conflito seria o dia 15 de março de 2011, quando estudantes grafitaram críticas ao governo de Bashar al-Assad nos muros da cidade de Damasco, a capital da Síria. Seguem-se depois repressões aos atos que ampliam as manifestações e dão vida aos grupos opositores ao governo (ANDRADE, 2011; FERRIS; KIRIŞCI, 2016; ZAHREDDINE, 2013). Cabe ressaltar que as respostas violentas à oposição não são uma novidade na dinastia Assad e na história Síria como um todo, tal como é exemplificado pela forte repressão que vitima por décadas a Irmandade Muçulmana Síria (FERREIRA; VANDERLEI; BELINATTI, 2016).

Não se pode perder de vista que o conflito na Síria é complexo e envolve diversos atores, dentre eles, o Estado Islâmico (ISIS), a Frente al-Nusra, grupos oposicionistas contra o governo, além de coalizões externas que apoiam grupos no conflito. Com relação aos atores externos, cabe destaque à Federação Russa, que é uma das maiores fornecedoras de armas para o governo sírio; outros, como Irã e Líbano, igualmente fornecem equipes e treinamento militar em favor do governo (FERRIS; KIRIŞCI, 2016). Em contrapartida, a Turquia, Qatar e Arábia 
Saudita treinaram grupos opositores ao governo e são acusados de armá-los. Além destes, os Estados Unidos também apoiaram grupos opositores, especialmente o Exército Livre da Síria (ELS), uma dissidência das forças armadas oficiais leais ao governo de Bashar al-Assad. Ainda, a maior potência militar do planeta atuou bombardeando locais controlados por grupos extremistas (FURTADO; RODER; AGUILAR, 2014).

Diferentemente de outros países que vivenciaram protestos no mesmo ano de 2011 e responderam com abertura democrática e maior representação social - tais como Jordânia e Bahrain -, o governo Assad escolhe seguir por um caminho pautado em uma opressão que impulsiona um conflito de proporções inimagináveis. Posteriormente, surgem diversos grupos com interesses diferentes no território, mas que possuíam o objetivo comum de retirar o presidente do poder. Um desses grupos é o ELS, que nasce de uma dissidência das Forças Armadas do governo Assad para então buscar uma transição do poder. Outro importante ator desde o início do conflito é a Frente Al-Nusra, que luta para estabelecer um Estado baseado em uma estrita interpretação da lei islâmica no país. Com ideologia similar, emerge também o ISIS (ou Estado Islâmico) que tem por objetivo principal expandir um califado para além das fronteiras sírias e dentro do Iraque. Por sua vez, os curdos que são a maior etnia sem território próprio reivindicam por autonomia, mas enfrentam oposição por parte principalmente da Turquia (SOARES, 2018)2. Cabe destacar aqui o papel fundamental das mulheres curdas que através de organizações autogestoras como o YPJ (Unidade de Proteção das Mulheres) demonstram desde o início do conflito um caso emblemático de atuação das mulheres diante da brutalidade do regime Assad (RIBEIRO, 2019).

\footnotetext{
Os curdos são uma população estimada entre 25 e 35 milhões que se espalham por cinco países: Turquia, Iraque, Síria, Irã e Armênia. Há uma hostilidade enraizada entre curdos e a Turquia pois, em 1978, Abdullah Ocalan fundou o Partido dos Trabalhadores do Curdistão (PKK) que reivindica uma região autônoma para os curdos no sudeste da Turquia. Fundamentado em suas ideias de confederalismo democrático, após seis anos o grupo iniciou uma luta armada contra a Turquia, cujas hostilidades permaneceram até 2013 quando um cessar-fogo foi acordado. Pouco depois, em 2015, o cessar-fogo é descumprido quando o governo turco lança uma "guerra sincronizada ao terror" contra o PKK e o Estado Islâmico (ISIS), ainda que ideologicamente os dois grupos estejam em polos opostos. Para mais detalhes, vide o excelente trabalho de RIBEIRO (2019).
} 
Com a intensificação do conflito, a disputa territorial entre o governo Assad e seus opositores se dissemina e gera uma violência desenfreada com uma profunda divisão territorial, que por sua vez resulta também em deslocamentos internos e fluxos migratórios de refugiados. Cidades com centenas de milhares de habitantes são rapidamente esvaziadas diante do poder de fogo que coloca de frente governo e grupos opositores. Desde seus primeiros dias, o conflito sírio já teve em sua totalidade mais de 13,2 milhões de refugiados e deslocados internos (LUQUINI, 2017; UNHRC, 2019). Especificamente, 6,6 milhões desses são refugiados sírios espalhados pelo mundo, sendo esta uma estimativa diante do alto número de saída de pessoas não registradas. Os refugiados sírios que saíram de seu país passaram a viver em campos e centro coletivos em geral inadequados (AKAR; ERDOĞDU, 2018). Um outro aspecto preocupante são as dificuldades para ter acesso à saúde, água, alimentação, educação e ajuda humanitária.

Os refugiados sírios se dirigiram para vários outros países, especialmente nações vizinhas como a Jordânia, Líbano, Iraque e Egito. Não obstante, um dos que mais têm acolhido os sírios refugiados é a Turquia, com um número estimado de 3,7 milhões de sírios segundo dados recentes (UNHCR, 2020). A Turquia é um dos países que faz fronteira com a Síria, mas seu envolvimento não se limitou apenas ao acolhimento de sírios. O governo de Recep Tayyip Erdogan tem apoiado rebeldes contra o governo desde o começo do conflito, além de também acolher opositores (SOARES, 2018).

Em 2018, a Turquia atuou com outras ações, como exemplificado com a construção de $764 \mathrm{~km}$ de muros em sua fronteira com a Síria e passou a ter presença no norte e noroeste daquele país como forma de combater o ISIS e as forças curdas próximas à sua fronteira. Já em fevereiro de 2020, a Turquia passou a conduzir operações terrestres na Síria com o intuito de criar uma "zona tampão" na fronteira e impedir tanto o avanço de grupos extremistas como de curdos sírios. Essa iniciativa de retomada e reconstrução apenas representa uma forma de exploração turca, pois ao expulsar curdos da região o governo Erdogan também conseguiu controlar o local e criar uma governança e conselhos locais para a administração, o que fez com que a região ficasse dependente política, 
econômica e militarmente da Turquia. Apesar disso,a iniciativa tem garantido alguns serviços básicos de segurança e suporte para essas áreas e para a população síria (LEEUWEN; VEEN, 2019; SOARES, 2018).

Além desse envolvimento no conflito sírio, a Turquia também acolheu milhões de refugiados, porém isso não era o esperado inicialmente pelo país. 0 número de refugiados cresceu significativamente após o acordo turco com a União Europeia (UE) em 2016, que previu em um dos seus principais pontos que todos os imigrantes irregulares que chegassem às ilhas gregas seriam devolvidos à Turquia. Com o crescimento exponencial do número de refugiados, o país também precisa lidar com desafios internos que emergem durante esses anos de acolhimento.

\section{A Turquia e o acolhimento humanitário de refugiados sírios}

A Turquia foi um dos países que mais recebeu refugiados sírios. No que concerne ao acolhimento e proteção internacional dessas pessoas, o país ratificou em 1951 a Convenção das Nações Unidas sobre o Estatuto dos Refugiados. Porém, destarte, o acolhimento turco previa se aplicar apenas para pessoas refugiadas de eventos ocorridos na Europa (IÇDUYGU; NIMER, 2019)³. Da mesma forma, o Protocolo de 1967 também manteve a limitação geográfica, logo, o "asilo" para os sírios seria inicialmente temporário (EMHRM, 2011).

A ACNUR é o órgão da ONU responsável por auxiliar o governo turco com relação ao status de refugiado e na identificação de possíveis soluções duráveis para o acolhimento deste grupo. Assim, aqueles refugiados que pedem permissão de residência em algum país devem, antes de tudo, se registrar na ACNUR.

Quanto ao acolhimento na Turquia, muitos sírios após o início do conflito em 2011 tentaram ir para aquele país. No entanto, o sistema regular de asilo turco concedia permanência temporária na qual, após um período, esses refugiados deveriam se dirigir para outros países. Porém, com o agravamento do conflito e

\footnotetext{
Como afirmado por Içduygu e Nimer (2019, p. 4), "Turkey, although a signatory of the 1951 Convention, retains the original geographical focus on Europe and did not initially give Syrians official refugee status either".
} 
mais civis atravessando a fronteira, o governo teve que mudar sua política e acolher um número de refugiados que crescia exponencialmente a cada ano (HOFFMANN; SAMUK, 2016).

O Euro-Mediterranean Human Rights Network (EMHRN), organização humanitária focada na questão dos direitos humanos, relatou em uma missão na Turquia em 2011 que naquele período estavam montados de cinco a seis campos operacionais para receber refugiados sírios. Diante da quantidade de pessoas requisitando acolhimento, nesse período inicial do conflito a Turquia anunciou que faria uma política de portas abertas para os sírios, fato que resultou na chegada de 78.409 refugiados até 2012.

No entanto, ainda em 2011, não se tinha noção da proporção a que o conflito chegaria e a crise humanitária que existiria. Logo, as autoridades turcas não tinham conhecimento e capacidade para planejar uma adequada política de acolhimento (LUQUINI, 2017). Em 2012, o país continuaria aberto a receber sírios, mas apenas 100.000 pessoas anualmente, o que implicaria que quando alcançasse esse número, haveria limitações para entrar na Turquia (BATALLA; TOLAY, 2018). Porém a situação saiu absolutamente do controle. Em 2014 já eram um total de 1.645 .000 refugiados, um montante que trouxe consigo desafios sociais marcantes para o país hospedeiro (ORSAM, 2015). Em 2015, a ACNUR registrou 4 milhões de refugiados sírios fora de seu país e 1,8 milhão na Turquia (UNHCR, 2015).

Duas das preocupações, principalmente nos anos de 2014 e 2015, foram a emergência e expansão de grupos tidos como mais radicalizados que estavam, fortemente atuantes em regiões da Síria que fazem fronteira com a Turquia, entre eles o ISIS. Logo, o desafio de manter as fronteiras abertas implicaria também em lidar com a ameaça do terrorismo e radicalização, o que era visto como um problema significativo para Ancara. Em razão disso, a Turquia fechou a fronteira para manter a segurança e controlar o fluxo migratório. Desse modo, os refugiados sírios ainda tiveram permissão para entrar, mas precisariam passar por uma segurança mais rígida. Isso não impediu o aumento de refugiados acolhidos no país que, já em 2016, era de mais de 2 milhões e, em 2017, 3 milhões. Diante desse aumento, os campos só poderiam acolher uma pequena parte 
desses sírios, restando aos demais uma marginalização e mendicância em áreas urbanas, principalmente em locais próximos da fronteira com a Síria (BATALLA; TOLAY, 2018; WEBER, 2017).

Entra aqui um papel mais atuante da Europa na crise. Desde meados de 2000, ela viu o crescimento exponencial de barcos improvisados com refugiados em busca de chegar às suas costas. Infelizmente, dezenas destes têm naufragado e gerado milhares de mortes. O ápice foi em 2015, quando um barco com migrantes naufragou com mais de 800 mulheres, crianças e homens. Diante das críticas da comunidade internacional à lenta e reticente resposta europeia, a União Europeia buscou essa aproximação com a Turquia para que os refugiados ficassem ali e não se arriscassem no mar Mediterrâneo.

Em consequência do acima explanado, o número de refugiados na Turquia cresceu após um acordo realizado entre o país e a União Europeia (UE) em 2016, visando diminuir a crise migratória. A Turquia era utilizada como rota pelos refugiados para chegar a outros locais, um deles a Grécia, para então seguirem para a Alemanha e outros países europeus. Por isso, a UE fez um acordo para que Ancara mantivesse os refugiados e migrantes em sua região e impedisse aqueles de atravessar a Grécia rumo aos demais países da Europa. Em contrapartida, a UE ficou responsável em contribuir com 3 bilhões de euros para ajudar os refugiados na Turquia, além de trabalhar pela aceleração dos processos de vistos e adesão da Turquia à UE (BABAN; ILCAN; RYGIEL, 2017). Desse modo, essa contribuição seria apenas uma transferência de fundos e assistência técnica em troca de um controle das fronteiras e restrições mais burocráticas e eficazes acerca da migração ilegal ou irregular. Não obstante, o acordo continua a demonstrar o descaso europeu com o tema, já que ao limitar a entrada de sírios através de um acordo meramente econômico e securitário com a Turquia, a UE ignora os aspectos sociais do problema. Ainda, a UE mostra aqui um marcante descompromisso internacional de proteger refugiados, dado que também são signatários da Convenção de Genebra (WEBER, 2017).

Outros procedimentos realizados pela Turquia foram anunciar em 2016 o requisito de visto para sírios que vêm de terceiros países, por via área ou marítima, e também regular a permissão de trabalho para os que já moram na 
Turquia por mais de seis meses. De modo geral, a situação desses refugiados na Turquia é muito variada e reflete aspectos de diversidade de níveis de classe e educação (HOFFMANN; SAMUK, 2016).

Apesar do empenho do governo turco em relação ao acolhimento dos refugiados, ainda é necessário que aconteça um trabalho conjunto para a integração desse grupo em seu sistema de proteção social. Esse trabalho em conjunto é ressaltado na Segunda Conferência de Bruxelas de apoio à Síria, organizada pela UE em 2018, em que se evidencia o importante papel de Ancara em garantir aos refugiados o acesso aos serviços como saúde, educação e emprego, mas também em apoiar o futuro da Síria. Nesse contexto, a conferência teve o propósito de mobilizar ajuda para os sírios e os refugiados em uma procura por uma solução política duradoura (ASSISTANCE, 2018).

\subsection{Os desafios domésticos no acolhimento de refugiados}

Ainda que a Turquia tenha assumido a responsabilidade de acolher os refugiados sírios, o crescimento do número desses refugiados trouxe ao país desequilíbrios econômicos, políticos e sociais. De acordo com Luquini (2017), no aspecto econômico, os gastos públicos passavam de 750 milhões de dólares e apenas 100 milhões vinham de ajuda externa. Outra problemática foi a social, diante da emergência de disputas entre comunidades locais turcas e os refugiados em busca de condições mínimas de trabalho (LUQUINI, 2017).

Acerca dos efeitos sociais, um dos principais desafios é a adaptação dos refugiados ao país. Ainda que se trate de países vizinhos, os refugiados sírios se deparam com um estilo de vida, cultura e idioma diferentes, além do desafio da construção de laços sociais com a população local. Algumas problemáticas que se disseminam na Turquia após seu acolhimento massivo aos refugiados sírios foram: aumento da poligamia, já que muitos turcos começaram a casar com sírias; trabalhos irregulares e relações forçadas; abuso infantil e de mulheres; e expansão urbana caótica em certas regiões do país. Especificamente sobre o trabalho infantil, poucas crianças fora dos campos possuem o acesso adequado à educação, fazendo com que famílias se sujeitem a trabalhos degradantes para sua sobrevivência (ORSAM, 2015). 
Sobre a economia, apesar dos sírios poderem contribuir para a economia local e nacional, alguns aspectos negativos são o aumento do aluguel e dos alimentos nas cidades turcas. A taxa de desemprego na Turquia também cresceu e recentemente está em 13,2\%4, o que fez a sociedade turca culpar cidadãos sírios pelo seu aumento. Mas esses refugiados também se tornaram um ator econômico na Turquia, dadas suas habilidades e em razão do fato dos produtos fornecidos nos campos de refugiados sírios serem produzidos por empresas turcas (BOLUK; ERDEM, 2016).

Sobre os efeitos políticos e de segurança, o Centro de Estudos Estratégicos do Oriente Médio (ORSAM, na sigla em inglês) (2015), think-tank de estudos de relações internacionais baseado em Ancara (Turquia), destaca que se acentuou a possibilidade de conflitos locais e preocupações com a segurança ao acolher esses refugiados, o que também foi ressaltado por Batalla e Tolay (2018) ao enfatizarem que a Turquia ampliou sua segurança devido a atividades terroristas em regiões próximas à fronteira. Igualmente são uma preocupação os conflitos internos referentes às frustações de civis por causa do acolhimento aos refugiados sírios. Tal situação também contribuiu para uma desestabilização interna na Turquia, o que fez o país limitar a entrada de novos refugiados e considerar deportação em casos de atos violentos (GHOTME; SICARD, 2016).

Outro problema enfrentado pelo país é a quantidade de refugiados fora dos campos que não estão identificados ou registrados. Esse fato levou o governo a controlar e limitar os movimentos de sírios na Turquia demandando que os refugiados residam na província em que foram registrados para ter acesso aos serviços básicos. Em 2018, a Turquia passou a coordenação e controle dos campos, assim como o acolhimento dos refugiados e suas necessidades, para a Direção Geral para Gerenciamento de Migrações (DGGM), que é a autoridade administrativa responsável por assuntos gerais de migração e proteção internacional. A instituição se empenha em montar uma estratégia de longo prazo para as principais necessidades e cuidados desses civis, tanto dentro como fora dos campos de refugiados (BATALLA; TOLAY, 2018).

\footnotetext{
4 Turquia Taxa de Desemprego. Disponível em:

https://www.ceicdata.com/pt/indicator/turkey/unemployment-

rate\#: :text=Os\%20dados\%20de\%20Taxa\%20de,14.10\%20\%25\%20em\%202020\%2D06. Acesso em: 25 fev. 2021.
} 
Apesar dessas mobilizações e iniciativasnão são tão claros os efeitos das políticas públicas turcas de asilo/acolhimento, assim como o número preciso de refugiados em seu país. Soma-se a esses problemas o desafio global que emerge em 2020 na China, identificado inicialmente em Wuhan: o mortal vírus conhecido por coronavírus (COVID-19). Como é sabido, este se espalhou por diversos locais e logo foi reconhecido como uma pandemia de acordo com a Organização Mundial da Saúde (OMS) (BBC, 2020).

Em razão da forma de transmissão ser principalmente pela proximidade entre as pessoas, o número de casos e, também, de mortes cresceu exponencialmente na Turquia. Na medida em que a pandemia do novo coronavírus avança, alguns grupos sociais se encontraram em posições vulneráveis. Um desses grupos é o de refugiados que se encontram em situação precária em campos, abrigos ou dispersos em territórios dos países, muitas vezes sem o acesso mínimo a saneamento e água potável (CORDEIRO, 2020).

Com o baixo acesso que se tem à assistência social e aos serviços de saúde, há consequentemente uma tendência de que exista aglomeração de pessoas, o que dificulta a contenção da propagação do COVID-19. Sobre a Turquia, o país teve seu primeiro caso em 11 de março de 2020, e inicialmente cresceu bastante o número de casos confirmados. Com esse desafio, na pandemia o país tomou medidas para reduzir a disseminação do vírus, o que inclui fechar escolas, recomendar isolamento, reduzir o movimento de pessoas acima de 60 anos e com menos de 20 anos, além de fechar comércios não essenciais (PERTEK; PHILLIMORE; MCKNIGHT, 2020).

O surto de COVID-19 parece ter afetado os refugiados sírios em diferentes aspectos; entre eles a perda de empregos, a falta de acesso à saúde e a dificuldade para que necessidades urgentes sejam atendidas. Desse modo, além de como conseguir integrar esses refugiados no país, a Turquia também tem que se preocupar em como conseguir que suas principais necessidades sejam atendidas, principalmente para os que estão fora dos campos, dado que o controle e disseminação de informação pode ser mais viável dentro dos campos do que para os que estão espalhados pelo país (RELIEF INTERNATIONAL, 2020). As incertezas sobre como ficarão esses refugiados sírios fazem refletir sobre as 
possibilidades para esse acolhimento realizado pela Turquia, assim como o possível retorno desses sírios para o seu país de origem.

\section{Os cenários e desdobramentos para o acolhimento de refugiados sírios na Turquia}

O principal motivo que provocou o grande número de refugiados sírios acolhidos em vários países foi o conflito armado em seu país. Para entender as possíveis perspectivas e desdobramentos do acolhimento de refugiados sírios na Turquia, é preciso partir do principal problema ainda em andamento, que é a Guerra Civil Síria.

Desse modo, são apresentados em seguida três cenários. No primeiro, a guerra civil continua e não há muito apoio externo para o acolhimento dos refugiados; segundo, um cenário em que o conflito tem uma conclusão, mas há limitações sociais e políticas para o retorno dos refugiados; e, por fim, um cenário alternativo, no qual apesar do conflito poder continuar por mais tempo, medidas de integração e reassentamento aconteceriam.

Como o futuro é imprevisível e apresenta diversas variáveis e atores que se relacionam na mudança de contexto a partir de suas ações, se torna importante, de acordo com Marcial (2015), construir análises de tendências. Estas levam em consideração as principais forças atuantes no ambiente social e político atual, assim como estes podem alterar o curso dos acontecimentos. Logo, para construir as três perspectivas aqui propostas tivemos como ponto de partida a Guerra Civil Síria e seu possível desfecho, para em seguida pensar no acolhimento desses refugiados a partir de três aspectos: a permanência/integração na Turquia; o reassentamento em outro país; e a reconstrução e retorno destes para seu país de origem. Em cada contexto se analisa qual poderia ser, entre esses aspectos, o desdobramento provável para o acolhimento desses sírios e o posicionamento turco.

Os estudos de cenários oferecem uma maneira de analisar contextos e os possíveis futuros alternativos (BUARQUE, 2003), especialmente na análise sobre fenômenos sociais em andamento na história do tempo presente. Com a 
percepção de que o futuro é incerto e indeterminado, principalmente ao pensarmos em um desfecho para a Guerra Civil Síria e como ficariam os refugiados, essa construção de perspectivas contribui para refletirmos quais seriam as possibilidades a partir dos cenários que temos no momento. Adicionalmente, permite levantar elementos e variáveis pertinentes para o estudo futuro de analistas que se dedicarão ao exame da temática aqui abordada.

\subsection{Cenário mais provável no médio prazo: a Guerra Civil Síria perdura e há limitação do apoio externo}

Segundo a ONU (2020), a Guerra Civil Síria não tem uma previsão exata para terminar e ainda é um processo incerto, em que sua finalização e a posterior reconstrução do país ainda não apresentam um horizonte claro. O retorno dos refugiados só seria possível com um contexto de paz e estabilidade, o que demandaria também reconstrução da infraestrutura do país (HOFFMANN; SAMUK, 2016).

No que se refere à Turquia, o país tinha interesse pela saída de Bashar alAssad e apoiava grupos opositores ao governo, mas recentemente tem marcado presença em território sírio e busca também fazer uma zona tampão. As motivações do governo turco, de acordo com discurso do presidente Recep Tayyip Erdogan, são combater o terrorismo e controlar a questão dos refugiados ao marcar presença em cidades na fronteira territorial entre os dois países e alojar parte desses refugiados no local (LEEUWEN; VEEN, 2019).

Nesse cenário em que a guerra perdura, independentemente de quais atores estarão envolvidos, ou as regiões da Síria em que há combates, a tendência é que civis sírios continuem saindo e requisitando refúgio em outros países, destacando-se a própria Turquia. No entanto, esta já acolhe mais de 3 milhões de refugiados sírios e, além de ser um grande número, o país é responsável por suprir as principais necessidades dessa população. Não seria surpresa então que o país priorizasse em sua política externa uma busca pelo reassentamento desses refugiados em um terceiro país ou a repatriação deles para áreas mais "seguras" na Síria (UNHCR, 2020) 
No início de 2020, o presidente turco ressaltou que o acordo realizado entre a Turquia e a UE não foi totalmente cumprido e, por isso, permitiria a abertura das fronteiras de seu país com a Europa. Esse posicionamento é também uma resposta à paralisação das negociações de acordos econômicos e políticos com o bloco europeu. O governo Erdogan também alega que o valor que a comunidade internacional repassa para a ajuda humanitária aos refugiados não é suficiente (DW, 2020). Caso a guerra perdure e o fluxo de refugiados também, as possibilidades podem ser que, primeiro, a Turquia permita que esses refugiados continuem seu percurso até a Europa, principalmente para a Grécia; segundo, que a Turquia consiga reconstruir e controlar uma parte do território sírio, para que assim alguns refugiados possam retornar; terceiro, que se faça uma integração mais efetiva desses refugiados em seu território.

Com o grande número de refugiados que a Turquia já possui, a opção de permitir o retorno de alguns deles para a Síria pode não ser uma das melhores opções caso a Guerra Civil Síria continue, visto que ainda haveria sírios requisitando refúgio enquanto não há estabilidade no país (MARCIAL, 2015). Além disso, o país já enfrenta alguns efeitos sociais e econômicos que, com a permanência do conflito e crescimento do número dos refugiados, podem se agravar, caso por exemplo, do descontentamento da população turca e conflitos internos, além do desemprego e falta de oportunidades (ORSAM, 2015).

Logo, a terceira opção, de integração, poderá também ser um desafio para o país. Seria preciso políticas públicas mais efetivas e relacionadas com a integração desses refugiados, assim como o financiamento externo para que os serviços nacionais fossem capazes de lidar com a quantidade de refugiados e também expandir as oportunidades para estes e os seus cidadãos. Porém, nem sempre as opções de integração e reassentamento são as possibilidades mais defendidas socialmente, o que torna o retorno desses refugiados a ideia mais reforçada com o contexto de se criar "zonas seguras". Não obstante, debater esse retorno sem uma solução pacífica efetiva na Síria pode ser problemático e esbarra na condição de "não devolução" do Estatuto dos Refugiados (IÇDUYGU; NIMER, 2019). 
Outra problemática é que apesar de existir o "Plano Regional de Resposta e Resiliência a Refugiados" (3RP), coordenada pela ACNUR e o PNUD (Programa das Nações Unidas para o Desenvolvimento), em 2019 as organizações arrecadaram apenas 58\% dos US\$ 5,4 bilhões necessários. A falta de ajuda externa, e o acesso limitado a serviços básicos, como o de saúde e educação, irá ocasionar em muitos refugiados a situação de vulnerabilidade, principalmente relacionada com exploração e abuso (ACNUR, 2020).

Outra incerteza é a pandemia do novo coronavírus. Para a UNICEF, ela tem o potencial de ser devastadora para refugiados, migrantes e deslocados, pois estes estão espalhados pelos países e até encontram dificuldades para ter acesso à saúde. Além disso, os campos abrigam muitos refugiados e isso tende a fomentar aglomerações, o que pode ser perigoso para a propagação do vírus. Dessa forma, além de se preocupar em como manter o acolhimento desse grupo, também é preciso lidar com o contágio em seu país e garantir a proteção dos mais vulneráveis.

A Turquia não está entre os países que mais tem casos ativos confirmados e deve continuar aplicando medidas, mas reabrindo seus outros serviços para conseguir lidar com os efeitos econômicos e sociais que já estavam em andamento no país (CORDEIRO, 2020). Apesar dessas medidas, a pandemia teve um impacto para os refugiados, pois 69\% perderam seus empregos e foram impactados também com o aumento dos custos de transportes, comida e saúde. No geral, o governo turco anunciou ajuda financeira para famílias em necessidade, mas é apenas uma medida emergencial e o país terá que buscar outras soluções (IFRC, 2020).

\subsection{Cenário contrastante: fim do conflito sírio e uma difícil reconstrução}

Para o retorno dos refugiados sírios ao seu país, seria preciso o fim das hostilidades e a reconstrução da região. No entanto, apesar do fim da guerra civil ser uma perspectiva otimista, para conter a crise humanitária seria necessário não somente o retorno dos refugiados. Dos possíveis cenários para o fim da guerra, um deles seria a retirada de Bashar al-Assad e a "vitória" da oposição, com o apoio dos Estados Unidos e de outros atores que desejam esse desfecho; 
outra opção seria que o governo conseguisse controlar todo o território novamente para enfraquecer decisivamente as hostilidades de seus opositores (DRAWIN, 2019).

Em cada uma dessas possibilidades, a Turquia poderia ter posicionamentos diferentes e a união com os Estados Unidos seria uma das tendências em caso da retirada de Bashar al-Assad. No entanto, a problemática está na vitória do governo atual, pois seria necessária ajuda externa para a reconstrução do país e sua reestruturação. Apesar de ter o apoio da Rússia, a Síria inicialmente não conseguiria lidar com todas as suas necessidades, sejam elas estruturais ou sociais. A realidade de alguns atores não se disporem a financiar essa reconstrução sob a batuta de Assad já é um fato e pode se tornar uma constante (MORAES, 2018).

Acerca do acolhimento humanitário dos refugiados sírios na Turquia, muitos destes se refugiaram por causa da guerra, mas existem sírios que também não concordavam com o governo de Bashar al-Assad, e retornar pode não ser uma opção viável por temor às suas vidas. Legalmente, um país receptor só precisa acolher, e não devolver o refugiado ao seu país enquanto o motivo que o fez pedir refúgio ainda permanece ativo. Mas em casos de um possível fim do conflito e na reconstrução do país, esses refugiados podem optar por ser tornar migrantes internacionais e começarem suas vidas em outros locais (FURTADO, 2017). Isso não seria uma opção viável para todos os refugiados sírios dado que muitos estão em campos ou não possuem uma renda alta, necessitando assim de ajuda humanitária fornecida pelos países e organizações internacionais.

Em síntese, ao examinarmos a situação do conflito sírio, não há uma perspectiva certa sobre sua conclusão. Ainda assim, 61.000 refugiados sírios retornaram da Turquia para a Síria entre 2016 e 2019. Mesmo com esse retorno, ainda é debatido se a repatriação é a saída ideal, pois o país continua com danos em sua infraestrutura, na provisão de água e eletricidade, e de centros médicos e escolas (IÇDUYGU; NIMER, 2019). Apesar de uma reconstrução já acontecer de forma gradual na parte ocidental da Síria e nos antigos mercados de Homs, ainda é preciso reestruturar locais como a periferia de Damasco e de Aleppo para uma 
reabilitação e construção de unidades habitacionais (RAZENTE, 2017). Também cabe salientar que a guerra ainda não acabou e o retorno desses refugiados continua a ser uma opção difícil, principalmente ao analisar como será a garantia das necessidades básicas dessa população (IÇDUYGU; NIMER, 2019).

\subsection{Cenário alternativo: o apoio internacional se intensifica e há integração e reassentamento dos refugiados}

Apesar de a Guerra Civil Síria perdurar em menor intensidade, se comparado ao seu ápice em meados da década de 2010, neste cenário o apoio internacional à Turquia permanece e também se intensifica diante da manutenção da incerteza quanto ao final do conflito. O país vai ter que se posicionar e visar as três principais soluções para o caso dos refugiados, que são: a possibilidade de retorno voluntário em alguns casos; reassentamento para um terceiro país; e, a integração desses refugiados na Turquia (BATALLA; TOLAY, 2018).

Em relação ao reassentamento, a ACNUR (2019) lançou um relatório, “Necessidades Globais de Reassentamento Projetadas para 2020", que colocava os sírios vivendo no país como os principais a serem realocados em um terceiro país devido à falta de soluções políticas para a resolução do conflito. A Turquia fica em destaque por ser o segundo maior polo, em que mais de 420 mil refugiados precisam ser transferidos. Considerando esses números, existe uma estratégia de, até 2028, realizar as chamadas "soluções de países terceiros" em benefício dos refugiados sírios que estão na Turquia, mas também em outros países.

Com essa alternativa, a tendência é que uma parte seja transferida para outros países, enquanto a outra utilize soluções distintas, entre elas retornar voluntariamente para a Síria ou migrar para outro local, ou se integrar ao país em que se encontra (ACNUR, 2019; XINHUA, 2018). Com a possibilidade de reassentamento, também é preciso lidar com a integração local no país que os acolheu, pois esses refugiados ainda vão enfrentar choque cultural, de idioma e educação. Este último porque a educação é fundamental para a integração, pois 
por meio desta se pode ter acesso ao idioma local, à cultura e à história do país receptor (AKAR; ERDOĞDU, 2018).

No caso de integração, significa que o acolhimento desse grupo não seria mais apenas um "fenômeno temporário", mas a Turquia teria decisões para implementar medidas e desenvolver uma política de integração que pudesse contemplar suas necessidades nacionais, e também englobar os refugiados que se encontram fora dos campos de acolhimento. Para isso, a Turquia faria uma estratégia de longo prazo, em que se preze a facilitar a educação, aprendizado da língua e direito ao trabalho, ou seja, mudaria sua atual estratégia de curto prazo, em que a ajuda emergencial acontece, mas pouco se desenvolve em políticas públicas relacionadas aos refugiados (HOFFMANN; SAMUK, 2016).

Para essa perspectiva, a Turquia necessitaria do suporte internacional para a inclusão dos refugiados em seus serviços nacionais. Os programas que já existem, como o EU Facility for Refugees in Turkey e o 3RP, têm o intuito de garantir assistência ao país que realiza o acolhimento para que este possa fornecer o necessário para os refugiados nas áreas da educação, saúde, apoio socioeconômico, emprego, entre outros. Esses programas teriam que permanecer e se ampliar para dar o suporte essencial para a integração desses refugiados (ACNUR, 2020).

Outro ponto seria que a Turquia continuaria a buscar soluções para facilitar o retorno dos sírios para seu país, mas ciente de que uma parcela desses refugiados iria permanecer em seu território por tempo indeterminado, dado que ainda não há o financiamento necessário para uma reconstrução urgente (MORAES, 2018). Em suma, nesse cenário se prevê principalmente uma integração e reassentamento de parte desses refugiados até 2028.

Para o desafio mais recente que é o da COVID-19, é necessário que se forneça uma assistência urgente aos refugiados sírios e o atendimento de suas necessidades básicas, mas que também se continue monitorando a situação do vírus para avaliar o possível impacto nos refugiados sírios que se encontram na Turquia. Medidas devem continuar a ser impostas, pois apesar de não ser um epicentro da pandemia, é preciso que se controle a propagação do contágio para que o país retome plenamente suas atividades. A pandemia também representa 
um desafio para os refugiados, pois estes têm acesso limitado aos serviços públicos e sofrem com a limitação imposta aos seus empregos informais (IFRC, 2020).

Por causa disso, a assistência aos refugiados é ainda mais importante, pois os grupos vulneráveis, sem informações e apoio, podem continuar espalhando o vírus e sobrecarregando o sistema de saúde (CORDEIRO, 2020; RELIEF INTERNATIONAL, 2020). Também é importante que sejam minimizados esses efeitos e as consequências advindas das mudanças que ocorreram após o início da pandemia, especialmente considerando que um dos aspectos essenciais do acolhimento humanitário consiste em assegurar as necessidades básicas desses civis. Assim, a Turquia e a comunidade internacional terão como árdua tarefa buscar soluções para garantir os principais direitos para seus 3 milhões de refugiados.

\section{Considerações finais}

Os refugiados são aqueles que saem de seu país de origem por causa de conflitos ou violências que ameacem suas vidas. Por conseguinte, esse grupo tem proteção internacional para que se possa garantir o seu acolhimento e as necessidades básicas. Esses refugiados só poderiam retornar para seu país de origem em dois casos, sendo que um deles é o retorno voluntário, e o outro no caso do fim do problema que o tenha levado a se refugiar. Logo, o país que os acolhe não pode os devolver para seu país de origem com base nas regulações internacionais vigentes.

Um caso particular com proporções extremas tem sido a Guerra Civil Síria. Esta tem feito com que vários civis ainda busquem refúgio em outros países, especialmente em nações vizinhas. A Turquia, em particular, acolheu muitos refugiados sírios, mas não era esperado que o prolongamento da crise atingisse os 3 milhões de pessoas em seu território até o momento. Este país tem visto que acolher uma grande quantidade de refugiados não é algo simples, pois muitos destes demandam condições básicas de trabalho e acesso à saúde e educação. Ainda, a política de asilo da Turquia garante status legal especialmente para refugiados europeus, emergindo aqui como desafio maior o gerenciamento 
de milhões de pessoas que não estão totalmente integrados em seu país legalmente e socialmente.

A partir dos cenários propostos anteriormente apresentados (fim do conflito, sua permanência, ou uma permanência com maior disposição de ajuda humanitária às vítimas civis) fica em evidência que é preciso pensar em políticas públicas efetivas que possam integrar esses refugiados na Turquia, assim como casos históricos têm demonstrado (ver FARIAS; FERREIRA, 2020). Urge também analisar as possibilidades de reassentamento de alguns destes para outros países, para que assim se possa garantir a proteção e cuidados necessários com essa população. Uma permanência do conflito tende a levar mais civis a pedirem refúgio, e, com o fim da guerra, ainda é incerto quando o retorno dos sírios seria possivel, quantos retornariam de fato e sob quais condições.

De modo geral, os desdobramentos do conflito e do acolhimento desses refugiados, ainda são incertos, pois a Turquia continuar a buscar e marcar presença geopolítica em território sírio, especificamente na fronteira entre os dois países na área controlada pelos curdos. Muito do futuro dos refugiados depende dos desdobramentos dessas intervenções militares.

Ainda assim, o principal apelo do país e de organizações internacionais e não governamentais, além da própria ACNUR, é que a comunidade internacional intensifique sua ajuda para esses refugiados sírios e contribua para as possíveis soluções em prol da proteção a este grupo. Esse apelo também é forte devido a COVID-19, pois os países precisam controlar o contágio e ao mesmo tempo pensar em como proteger e garantir a saúde dos grupos mais vulneráveis da sociedade.

Em suma, diante de um conflito contemporâneo que não tem perspectivas para seu fim e que desencadeia uma crise humanitária e de refugiados sem precedentes, nota-se a fundamental importância da mobilização internacional pela dignidade e proteção de civis que não escolheram sair de seu país de origem, mas que foram forçados a isso. Instrumentos foram historicamente criados para isso, mas as tensões geopolíticas ainda se mostram um entrave em busca de proteger a dignidade humana. 


\section{Referências}

ACNUR. Após 9 anos de tragédia, resiliência e solidariedade, o mundo não pode esquecer dos sírios. [Brasília]: ACNUR, 2020. Disponível em:

https://www.acnur.org/portugues/2020/03/11/apos-9-anos-de-tragediaresiliencia-e-solidariedade-o-mundo-nao-pode-esquecer-dos-sirios/. Acesso em: 25 jul. 2020.

ACNUR. Mais de 1,4 milhão de refugiados vão precisar de reassentamento em 2020. [Brasília]: Nações Unidas, 2019. Disponível em:

https://nacoesunidas.org/acnur-mais-de-14-milhao-de-refugiados-vaoprecisar-de-reassentamento-em-2020/. Acesso em: 25 jul. 2020.

AKAR, Sevda; ERDOĞDU, M. Mustafa Syrian refugees in Turkey and integration problem ahead. Journal of International Migration and Integration, Amsterdã, n.20, p. 925-940, 2019.

ANDRADE, George Bronzeado de. A guerra civil Síria e a condição dos refugiados: um antigo problema, "reinventado" pela crueldade de um conflito marcado pela inação da comunidade internacional. Revista de Estudos Internacionais, João Pessoa, v. 2, p.121-138, 2011.

BARICHELLO, Stefania Eugenia; ARAUJO, Luiz Ernani Bonesso de. Aspectos históricos da evolução e do reconhecimento internacional do status de refugiado. Universitas Relações Internacionais, Brasília, v. 12, n. 2, p. 63-76, jul./dez. 2014.

BABAN, Feyzi; ILCAN, Suzan; RYGIEL, Kim. Syrian refugees in Turkey: pathways to precarity, differential inclusion, and negotiated citizenship rights. Journal of Ethnic and Migration Studies, New York, v. 43, n. 1, p. 41-57, 2017.

BATALLA, Laura; TOLAY, Juliette. Toward long-term solidarity with Syrian Refugees? Turkey's Policy response and challenges. Atlantic Council, Washington, D.C., 2018. Disponível em: https://www.atlanticcouncil.org/in-depth-researchreports/report/toward-long-term-solidarity-with-syrian-refugees-turkey-spolicy-response-and-challenges/. Acesso em: 02 abr. 2021.

BBC. O que é pandemia e o que muda com declaração da OMS sobre o novo coronavírus. [São Paulo]: BBC News: 2020. Disponível em: https://www.bbc.com/portuguese/geral-51363153. Acesso em: 27 jul. 2020.

BOLUK, Gulden; ERDEM, Sukru. Syrian refugees in Turkey: between heaven and hell? IEMED: Mediterranean Yearbook, Madrid, n. 2016, p. 1-4, 2016. 
ASSISTANCE to Syrian refugees in Turkey. In: BRUSSELS CONFERENCE, 2018, Brussels. Conference document [...]. [Brussels]: European Council Council of the European Union, 24-25 April 2018. Disponível em:

https://www.consilium.europa.eu/media/34146/turkey-partnership-paper.pdf. Acesso em: 26 de jul de 2020.

BUARQUE, Sérgio C. Metodologia e técnicas de construção de cenários globais e regionais. Texto para discussão no 939. Brasília: IPEA, 2003. p.1-43

CORDEIRO, Rui. Covid-19: milhões de refugiados enfrentam cenário de contágio iminente. TVI24 Internacional, [S.l], 9 abr. 2020. Disponível em:

https://tvi24.iol.pt/internacional/coronavirus/covid-19-milhoes-de-refugiadosenfrentam-cenario-de-contagio-iminente. Acesso em: 26 jul. 2020.

DRAWIN, Maria Clara. O fim do Estado Islâmico e os possíveis cenários para a Guerra na Síria. In: CONJUNTURA INTERNACIONAL: PUC Minas, [Belo Horizonte], 2 jul. 2019. Disponível em:

https://pucminasconjuntura.wordpress.com/2019/07/02/o-fim-do-estadoislamico-e-os-possiveis-cenarios-para-a-guerra-na-siria/. Acesso em: 25 jul. 2020.

DW. Turquia abre fronteiras a refugiados que querem chegar à Europa. DW Internacional, Berlim, 2020. Disponível em: https://www.dw.com/pt-002/turquiaabre-fronteiras-a-refugiados-que-querem-chegar-\%C3\%A0-europa/a52619436\#: :text=0\%20Presidente\%20turco\%2C\%20Recep\%20Tayyip,entre\%20as\%20p artes\%20em\%202016. Acesso em: 27 jul. 2020.

EMHRM. Syrian refugees in Turkey: a status in limbo. Copenhague: EuroMediterranean Human Rights Network, oct. 2011. p. 01-18.

FARIAS, Nivaldo Inojosa; FERREIRA, Marcos Alan S. V. Refugiados da Birmânia na Tailândia: da solidariedade à criação de políticas públicas. In: CARLETTI, Anna; NOBRE, Fábio R. F.; FERREIRA, Marcos Alan S. V. Relações Internacionais e religião: reflexões rumo a um contexto pós-laicista. João Pessoa: Editora UFPB, 2020. p. 236-282.

FERREIRA, Marcos Alan S. V.; VANDERLEI, Gary R.; BELINATTI, Gisele. A formação histórica e o engajamento político da Irmandade Muçulmana síria sob a perspectiva da Teologia Pública. Brazilian Journal of International Relations, Marília, v.5, n.2, p. 317-341, mai./ago. 2016.

FERRIS, Elizabeth; KIRIŞCI, Kemal. The context, causes, and consequences of syrian displacement. In: FERRIS, Elizabeth; KIRIŞCI, Kemal. The consequences of chaos: Syria's humanitarian crisis and the failure to protect. Washington D.C.: Brookings Institution Press, 2016. p. 01-32. 
FURTADO, Êrika Rigotti. O Problema dos refugiados sírios na Europa e a teoria da justiça de John Rawls. Revista de Direito, Viçosa, v.09, n.02, p. 61-85, 2017.

FURTADO, Gabriela; RODER, Henrique; AGUILAR, Sergio L. C. A guerra civil Síria, o Oriente Médio e o sistema internacional. Observatório de conflitos internacionais, Marília, v. 1, p.01-06, dez. 2014.

GARCÍA, Sergio; MASSARAT, Leila Sant. Religión y sociedade: movimientos migratorios, integración y cohesión social. Revista Brasileira de Políticas Públicas e Internacionais, João Pessoa,v. 4, n. 2, p. 05-24, 2019.

GHOTME, Rafat; SICARD, Nadia García. Los refugiados sírios como "problema" de seguridade regional. Estudios de Asia y África, Madrid, v. 51, n. 2, p. 365-390, 2016.

GOOGLE NEWS. Coronavírus (COVID-19). [S.l.]: Google notícias, [c2020].

Disponivel em: https://news.google.com/covid19/map?hl=pt-

BR\&mid=\%2Fm\%2F02j71\&gl=BR\&ceid=BR\%3Apt-419. Acesso em: 28 set. 2020.

HOFFMANN, Sophia; SAMUK, Sahizer. Turkish immigration politics and the Syrian refugee crisis. Working Paper: Division Global Issues, n: 01, p. 01-30, 2016.

IÇDUYGU, Ahmet; NIMER, Maissam. The politics of return: exploring the future of syrian refugees in Jordan, Lebanon and Turkey. Third World Quarterly, Londres, v. 41, n. 3, p. 415-433, 2019.

IFRC. Impact of COVID-19 on refugee populations benefitting from the emergency social safety net (ESSN) programme. Istambul: International Federation of Red Cross and Red Crescent Societies (IFRC): Assessment Report, 2020. p. 01-12.

IMDH (Instituto Migrações e Direitos Humanos). Migrações, refúgio e apatridia: guia para comunicadores. 1. ed. Brasília: IMDH-Migramundo-Ficas-Avina-ACNUR, 2019. Disponível em: https://www.acnur.org/portugues/wpcontent/uploads/2019/05/Migracoes-FICAS-color_FINAL.pdf. Acesso em: 15 jul. 2020.

INOJOSA, Anne H. F. A questão da emigração e a convenção 94 da OIT. Revista eletrônica do Tribunal Regional do Trabalho da 9a Região, Curitiba, v. 8, n.81, p. 86-105, 2019. Disponível em:

https://juslaboris.tst.jus.br/handle/20.500.12178/162911. Acesso em: 15 jul 2020.

IOM. World Migration Report 2020 Launched. Genebra: International Organization for Migration - IOM, 2019. Available in: :

https://www.iom.int/news/world-migration-report-2020-launched. Access in: 27 jul. 2020. 
LEEUWEN, Jan van; VEEN, Erwin van. Turkey in northwestern Syrian: rebuilding empire at the margins. In: CLINGENDAEL: Netherlands Institute of International Relations. CRU Policy Brief. [Haia]: Clingendael, 2019. p. 01-11.

LOTERO-ECHEVERRI, Gabriel; PÉREZ-RODRIGUEZ, M. A. Migraciones em la sociedade contemporânea: correlación entre migración y desarrollo. Retos Revista de Ciencias de la Administración y Economía, Madrid, v. 9, n.17, p. 145159, 2019.

LUQUINI, Roberto de Almeida. Os refugiados da guerra civil da Síria. In: WOISCHNIK, Jan; THEMOTEO, Reinaldo J. (org.). Fluxos migratórios e refugiados na atualidade. 1. ed. Rio de Janeiro: Fundação Konrad Adenauer, 2017. v. 7. p. 113134. (Série relações Brasil-Europa).

MARCIAL, Elaine (org.). População e sociedade. In: MEGATENDÊNCIAS MUNDIAIS 2030: o que entidades e personalidades internacionais pensam sobre o futuro do mundo? Contribuição para um debate de longo prazo para o Brasil. Brasília: Ipea, 2015.

MORAES, Hebert. Reconstrução da Síria passa pela saída do ditador Bashar alAssad do poder. Jornal Opção, Goiânia, edição 2268, 2018. Disponível em: https://www.jornalopcao.com.br/colunas-e-blogs/direto-do-orientemedio/reconstrucao-da-siria-passa-pela-saida-do-ditador-bashar-al-assad-dopoder-2-153665/. Acesso em: 25 jul. 2020.

ONU. Síria: um conflito trágico sem fim à vista. In: NAÇÕES UNIDAS: centro regional de informações para a Europa Ocidental, 2020. Disponível em: https://unric.org/pt/siria-um-conflito-tragico-sem-fim-a-vista/. Acesso em: 25 jul. 2020.

ORSAM - The Center for Middle Eastern Strategic Studies. Effects of the Syrian Refugees on Turkey. ORSAM Report, Ancara, n. 195, Jan. 2015.

PATARRA, Neide Lopes. Migrações Internacionais: teorias, políticas e movimentos sociais. Estudos Avançados, São Paulo, v. 20, n.57, p. 7-24, 2006.

PERTEK, Sandra; PHILLIMORE, Jenny; MCKNIGHT, Pip. Forced Migration, SGBV and COVID-19: Understanding the impact of covid-19 on forced migrant survivors of SGBV. In: IRIS: Institute for Research into Superdiversity. Birmingham: University of Birmingham, 2020.

RAZENTE, Bruno Rizzi. Reconstrução da Síria: um caminho para a paz hoje. Nexo, São Paulo, 3 set. 2017. Disponível em: https://www.nexojornal.com.br/ensaio/2017/Reconstru\%C3\%A7\%C3\%A3o-das\%C3\%ADria-um-caminho-para-a-paz-hoje. Acesso em: 18 out. 2020. 
RELIEF INTERNATIONAL. Impact of the COVID-19 outbreak on Syrian refugees in Turkey. [S.l.]: RI Turkey, 2020.

RIBEIRO, Maria Florencia Guarch. A trajetória do movimento de mulheres no Noroeste do Curdistão: a institucionalização da Jineologî (1978-2018). 2019. Dissertação (Mestrado em Ciência Política) - Universidade Federal do Rio Grande do Sul, 2019.

SALKIND, Neil J. Triangulation. In: ENCYCLOPEDIA OF RESEARCH DESIGN. Thousand Oaks: SAGE Publications, 2010

SHARMA, Bonita B. Revisiting the United Nations' 1951 convention relating to the status of refugees: a critical analysis of the international refugee law. Social Development Issues, Chicago, v. 37, n. 2, 2015.

SOARES, João V. S. A guerra civil na Síria: atores, interesses e desdobramentos. OCl-Observatório de Conflitos Internacionais: Série Conflitos Internacionais, Marília, v.5, n.1, 2018.

SPINDOLA, Marielle. Uma análise da condição dos refugiados sírios à luz da dignidade da pessoa humana. Revista da ESMESC, Florianópolis, v. 25, n. 31, p. 6183, 2018.

SOHR - SYRIAN OBSERVATORY FOR HUMAN RIGHTS. Nearly 585,000 people have been killed since the beginning of the Syrian Revolution. SOHR, Coventry, 2020. Disponível em: https://www.syriahr.com/en/152189/. Acesso em: 27 set. 2020.

UNHCR. Global trends: forced displacement in 2019. In: UNHCR - The UN Refugee Agency. [S.l]: UNHCR, 2019. Disponível em:

https://www.unhcr.org/5ee200e37/\#_ga=2.168484705.1537457022.16026110861428379179.1601409666. Acesso em: 12 out. 2020.

UNHCR. Refugee data finder. In: UNHCR: The UN Refugee Agency. [S.l]: UNHCR, 2020. Disponível em: https://www.unhcr.org/refugee-statistics/. Acesso em: 27 jul. 2020.

UNHCR. Total number of Syrian refugees exceeds four million for first time. In: UNHCR - The UN Refugee Agency. [S.l]: UNHCR, 2015. Disponível em: https://www.unhcr.org/news/press/2015/7/559d67d46/unhcr-total-numbersyrian-refugees-exceeds-four-million-first-time.html. Acesso em: 12 out. 2020.

WEBER, Bodo. The EU-Turkey Refugee Deal and the not quite closed balkan route. Friedrich Ebert Stiftung, Berlim, Jun. 2017. 
XINHUA. Análise de notícias: refugiados sírios na Turquia precisam de mais reassentamento, segundo analistas. XinhuaNet, Pequim, 2018. Disponível em: http://portuguese.xinhuanet.com/2019-11/18/c_138563735.htm. Acesso em: 25 jul. 2020.

ZAHREDDINE, Danny. A crise na Síria (2011-2013): uma análise multifatorial. Revista Conjuntura Austral, Porto Alegre, v. 4, n. 20, p.06-23, nov. 2013. 